\title{
No cinema de Woody Allen os sujeitos pós-modernos com suas neuroses nas cídades de Nova York, Barcelona e Paris
}

\author{
Elis Crokidakis Castro \\ FACHA, Brasil \\ Luís Antônio Monteiro Campos \\ PUC, UNESA, UCP, Brasil
}

\begin{abstract}
Many labels have been critically placed in Woody Allen's films, but throughout his career the filmmaker and screenwriter has, from time to time, films that astonish audiences by the diversity of themes on display. Such a surprise happens mainly in 3 films that may seem old by their release dates but have themes that continue to be relevant in the life of postmodern cities and within an analysis of Western culture, we see in the films: Deconstructing Harry (1997) Vicky and Cristina Barcelona (2008), Midnight in Paris (2011). Starting from these films our look will be destined to New York, Barcelona and Paris and we will try to show how to live or to be in these cities can be one of the constituent partial elements of the subjectivity of these personages that comes to interfere, predominantly, in the psychological of them, that is, we will see as through the cinematographic art we can represent to represent the neuroses and psychoses of the real and imaginary personages that inhabit the big cities.

Our theoretical base will pass through the scholars of the phenomena of the cities in their schools: German, French, Anglo-Saxon American and its theories, as well as theorists of psychology and philosophy.
\end{abstract}

Keywords: Cinema, Psychology, Cities, Wood Allen

\section{Introdução}

No cinema de Woody Allen os sujeitos pósmodernos com suas neuroses nas cidades de Nova York, Barcelona e Paris.

Nova York, Barcelona e Paris essas são as três cidades que constituem o espaço dos filmes que analisaremos nesse artigo, onde procuramos mostrar como viver ou estar nessas cidades pode ser um dos elementos parciais constituintes da subjetividade dos personagens e como isso vem a interferir, predominantemente, no psicológico deles, ou seja, veremos como através da arte cinematográfica podemos dar conta de representar as neuroses e psicoses dos personagens reais e imaginários que habitam as grandes cidades.

Não é de hoje que a arte serve como uma forma dos seres humanos representarem a sua realidade e isso é fundamental na sua constituição enquanto ser pensante, que se relaciona com outros seres e faz interpretações. Por mais que erradamente se pense que a arte talvez não seja de fato algo que tenha funcionalidade enquanto objeto, ela todavia serve e sempre serviu como forma de expressão do homem que busca na realidade a sua matéria bruta para transformar em linguagem, seja ela fílmica, literária, pictórica, teatral etc. No entanto, a arte não é a realidade, ela, segundo Aristóteles, é a sua reapresentação, a partir dos olhos de quem pinta, de quem escreve, de quem atua.

Se na Grécia antiga e também em outras culturas o teatro fazia a população se ver no espelho do palco, hoje temos no cinema, ou no áudio visual, uma maneira de se fazer o mesmo. Vendo-se na tela, funcionalizando a realidade talvez tenhamos mais possibilidade de compreende-la, de entender seus mistérios, de mudar a rota se ela não estiver correta, ou mesmo nos conformar com o que vemos.

Cinematograficamente são inúmeros os diretores e roteiristas que tentam dar conta de tudo que está acontecendo ao seu redor e levar a sociedade a pensar sobre si mesma. Diriam alguns que isso é ilusão, que o cinema é ilusão e nada muda na sociedade, até porque ele atinge poucos, mas nossa visão é diversa. Sabemos que desde o nascimento dessa arte ela de fato teve um papel importantíssimo na transformação da forma de viver do planeta. Foi pela imagem e movimento que questões políticas, sociais e econômicas puderam ser conhecidas em todo globo terrestre e isso teve um impacto no crescimento que tivemos no século XX. Toda transformação na maneira de ser do homem e até mesmo nos seus sentimentos em algum momento teve a ver com o cinema. Por exemplo, podemos pensar nas relações amorosas que a partir de Hollywood foram eternizadas como modelo de amor em filmes como Casablanca por exemplo. Também foi pelo cinema que as imagens da guerra chegaram aos olhos do planeta, na primeira guerra midiática que foi a II Guerra Mundial. Ainda pelo cinema, que é fotografia em movimento, que podemos ter acesso aos mais diferentes movimentos sociais acontecidos no século XX. Não que todas essas coisas fossem desconhecidas, não eram, existiam jornais, romances, ou seja, narrativas que eram construídas para explicar e dar informações sobre a realidade. Entretanto, uma coisa é narrativa construída a partir de um ponto de vista verbal escrito e outra é a construída com imagens, reais ou por representação. Sabemos que o discurso imagético pode, tal como o verbal, ser manipulado, mas ele sempre poderá ser mais exposto a dúvida de quem olha. Ou seja, nem sempre o que olhamos, assim como o que lemos, é o que literalmente se diz. As metáforas podem ser trabalhadas tanto na linguagem verbal como na escrita e ao interpretarmos podemos ainda mergulhar num universo de sentidos e valores ilimitados.

No sentido metafórico é que muitas vezes o cinema faz questão de trabalhar, falamos aqui principalmente 
da ficção que vai vasculhar o sujeito que vive na nossa pós modernidade e com esse personagem é que o espectador vai se relacionar numa relação quase hipnótica como nos diz Guattari $(1992,153)$ já que "no cinema, o corpo se encontra radicalmente absorvido pelo espaço fílmico" (Guattari,1992,153).

Importante dizermos que nesse momento a vida no planeta passa por um estágio muito peculiar devido à grande massificação dos veículos de comunicação, que nascem com o propósito de criar inteiração entre pessoas, mas que talvez, em vez disso, esteja distanciando as pessoas, causando vários outros problemas inclusive de ordem psicológica e isso ocorre especificamente no espaço das cidades, ou das metrópoles e megalópoles da pós modernidade.

O estudo sobre os problemas que vem surgindo no sujeito que habita as cidades está na ordem do dia das pesquisas, segundo Guattari em seu texto "Espaço e corporeidade", citando o psiquiatra e etnólogo Daniel Stern (The impersonal world of the infant), há um caráter polifônico da subjetividade, e por isso ela vem sendo talvez desvendada em todas as suas nuances e dentro dessa polifonia se encontra o elemento espacial. Tendo consciência ou não, o espaço em que vivemos vai nos interpelar de diferentes modos: estilístico, histórico, funcional, afetivo etc, diz o filósofo em questão, e essa interpelação produz uma "subjetivação parcial que se aglomera com outros agenciamentos de subjetivação. Um bairro pobre ou uma favela fornecem-nos um outro discurso e manipulam em nós outros impulsos cognitivos e afetivos" (Guattari,1992, 158), como mostram nossos filmes examinados onde temos a diversidade de personagens que vivem Nova York, que passam por Paris e que habitam e passam por Barcelona.

Também no sentido do entendimento dessa questão acima é que se colocam alguns estudiosos das cidades, nas suas mais variadas teorias.

Nesse contexto está o sociólogo e historiador Lewis Mumford da Escola Anglo Saxônica americana que desenvolve o conceito de cidades como megamáquinas, lugar de encontros, onde nasce a cultura, responsável pela ruptura do nomadismo e o início da vida sedentária, sendo as mulheres a principal responsável por esse fenômeno na história da humanidade (Freitag,2016,111). Os componentes dessa máquina, então, são entendidos como produtores da subjetividade, todavia não é toda a subjetividade, mas parte dela. Assim temos numa mesma sociedade pessoas que se diferem em comportamentos por habitarem diversos lugares dentro de uma mesma cidade, num aspecto local, embora em nível global tenhamos agora problemas que transpõem um espaço local reverberando no global. Quem fala isso é a socióloga holandesa Saskia Sassen em seu livro "As cidades globais", segundo a autora hoje as decisões tomadas nas grandes metrópoles como Nova York, Londres etc, acabam repercutindo em todo o globo sendo isso um efeito da economia globalizada que pode destruir ou revitalizar de um momento para outro grandes centros urbanos, ou bairros das cidades.
Ou seja, a condição global da economia hoje, faz com que mude o status dos espaços às vezes de forma muito rápida, reorganizando as cidades contemporâneas e atuando diretamente na subjetividade dos seus moradores. Esse fenômeno é o que por exemplo no Brasil percebemos nos últimos anos, especialmente no Rio de Janeiro quando com o auge do crescimento econômico tivemos um investimento grandioso para um desenvolvimento de pequenas cidades como Macaé, Itaboraí e que com a crise política e econômica foram completamente devastada em investimentos ficando seus moradores afetados diretamente em suas posses, empregos e vida. Tais cidades possuem bairros que viraram fantasmas de uma possibilidade que não ocorreu causando imensa frustração, com problemas sociais e de ordem emocional em seus habitantes.

Em outro aspecto a globalização pode ser percebida também pelo sentimento de desterritorialização que para Fernandes é "precisamente a quebra do controle de cada indivíduo, comunidade ou empresa sobre o seu território: no caso específico das populações, essa implica uma quebra de vínculos, uma perda de território, um afastamento aos respectivos espaços de afirmação material e/ou imaterial, funcional e/ou simbólica" (Fernandes, 2008), onde os sujeitos não se sentem pertencer a nenhum lugar ou a grupo e isso significa que as relações entre o corpo, a cidade, o clã, a cultura, de certa forma estão sendo reconfiguradas. Todavia esse processo não é tão simples resultando em inúmeros problemas que assolam as cidades e as populações principalmente no que toca a identidade desses sujeitos.

Estar em um shopping em qualquer lugar do mundo é a mesma coisa, promove o mesmo sentimento. Os espaços são padronizados impossibilitando a movimentação e promovendo certa paralisia nas sensações humanas. No shopping não há diversidade tudo é igual, desde o comportamento esperado do sujeito que ali anda, até os objetos da decoração vendidos nas lojas que são quase as mesmas em todo mundo, principalmente a julgar pelas grandes cadeias internacionais de lojas, assim como a forma como as pessoas se vestem para ali flanar. Hoje os corpos dóceis pelo consumo transitam com seus uniformes na cor da moda (tendência da estação), e seus celulares com capinhas e sem qualquer possibilidade de inclusão do indivíduo que não corresponda a esse código.

Sem dúvida a sociedade não passaria impune por esse fenômeno e uma das consequências é a fragilização dos laços humanos na contemporaneidade, o mal estar, além de outros tantos problemas psicológicos como depressão, síndromes derivadas do tipo de trabalho, pânico etc.

O sociólogo Zygmunt Bauman também tenta dar conta desse fenômeno da globalização nas cidades em seu mais famoso livro "Amor Líquido", que trata exatamente dessa fragilidade dos laços humanos na contemporaneidade. Para Bauman "as cidades contemporâneas são áreas de descarga para os produtos malfeitos e deformados da fluida sociedade 
moderna (embora elas próprias certamente não deixem de contribuir para a acumulação de dejetos)" (Bauman,2004,140). Essa seria então uma das causas de termos os laços humanos atuais tão frágeis nos levando a um momento antes nunca visto. No entanto, o autor para chegar nesse ponto, desenvolve sua tese que contempla além da análise do amor e da morte toda a forma como nós hoje estamos nos relacionando. Um dos aspectos mais interessantes diz respeito a fugacidade e efemeridade também dos relacionamentos, o não comprometimento das pessoas, os milhões de amigos virtuais que temos pela internet, a facilidade de fazer e desfazer amizades e a ansiedade que tudo isso provoca. Diz-nos o sociólogo que junto a grande e poderosa tentação de apaixonar-se está a atração em escapar. Ou seja, vivemos no limite entre estar dentro e fora o tempo todo. Talvez desterritorializados dentro de nós mesmos. Qualquer problema já é por si só motivo para o escape seja ele do jeito que for, através do consumo, do uso de drogas lícitas ou ilícitas, arte ou qualquer outro tipo de possibilidade. Homens e mulheres que são a paisagem humana desses espaços citadinos apresentam-se perdidos entre o espaço que é físico e também o virtual e nessas paisagens, diz Bauman, é que são registradas as vacilantes aspirações existenciais. Assim,

as cidades contemporâneas são campos de batalha em que os poderes globais e os significados e identidades obstinadamente locais se encontram, se chocam, lutam e buscam um acordo que se mostre satisfatório ou pelo menos tolerável- um modo de coabitação que encerre a esperança de uma paz duradoura, mas que, em geral, se revela um simples armistício, um intervalo para reparar as defesas avariadas e redistribuir as unidades de combate. É esse confronto, e não algum fator singular, que coloca em movimento e orienta a dinâmica da cidade "líquido-moderna" (Bauman, 2004, p.126)

$\mathrm{Na}$ cidade tudo ainda é mais complicado, ao reparamos que homens e mulheres que habitam esses espaços estão cada vez mais contaminados por ele,

e nos lugares e a partir deles que os impulsos e desejos humanos são gerados e incubados, que vivem na esperança de se realizarem, que se arriscam a se frustrar e, na verdade, com muita frequência, se frustram. (Bauman, 2004, p.124),

que é o que nos mostram tanto os personagens de muitos filmes. Nos filmes o que mais é questionado e mostrado, através de metáforas e do próprio discurso dos personagens e suas ações é essa frustração. Quando buscam parcerias amorosas e isso não vinga, quando discutem assuntos de ordem mais pessoal que denotam a fragilidade de suas interações e mesmo quando discutem assuntos de ordem global. Nesse sentido é que o fenômeno urbano é um modo de vida. A cidade, como já dissemos não é só o espaço, ela é a produtora de uma certa cultura, de formas de relações pessoais que só ali são possíveis, de valores específicos que atuam ali e não em outros pontos.

\section{Os personagens e as cidades}

Especificamente, os filmes de Woody Allen nos trazem inúmeras questões que podem ser incorporadas ao momento da pós-modernidade. No primeiro filme de três nosso olhar vai para o personagem Harry. É um filme onde o personagem é um escritor em crise, e conta as suas aventuras, desvelando seus recalques e mergulhando numa narrativa com um tom tanto sarcástico, quanto crítico. O próprio diretor é o ator do filme e é como se fizesse o personagem de si mesmo, por isso o grau de verossimilhança é tão alto. Todavia o que mais importa para esse ponto da análise é pensar o quanto a cidade de Nova York tem a capacidade de interferir na constituição desse sujeito. Ele vem de um lugar do interior, de uma faculdade que agora quer homenageá-lo justamente por ele ser um escritor de sucesso, mostrando um certo tom irônico nesse comportamento das instituições e parecendo que o diretor quer com isso pontuar a hipocrisia acadêmica.

No entanto, Harry que vem de casamentos falidos, de relações complicadas vividas no agito da grande metrópole, brinca com a questão. Ou seja, a loucura da cidade grande fez com que o personagem levasse à tona todos os seus aspectos mais pervertidos, coisas que na cidade pequena seria inviável. Somente na cidade grande, quando todos são desconhecidos se pode pagar uma prostituta para marcar presença fazendo companhia e ainda levar o filho sem que isso abalasse a moral conservadora das pessoas.

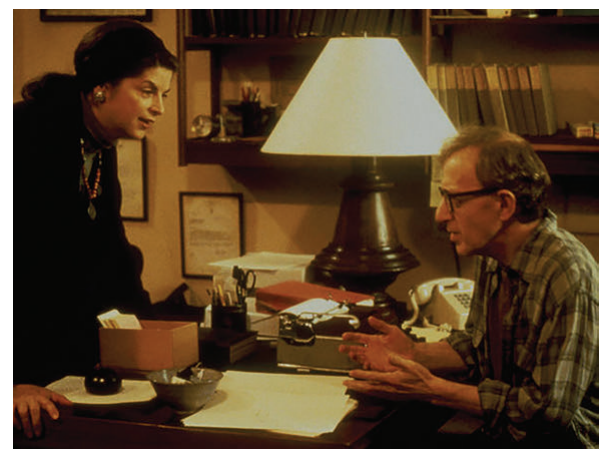

Figura 1

Harry é um personagem estranho e descontruído porque seria o anti- herói já que faz tudo contrário, é como um Macunaíma o herói sem caráter de Mario de Andrade. As ações que dão movimento a trama também refletem a inconstância que se vive na grande cidade. Existe uma necessidade humana de relacionar-se mas que por circunstâncias nem sempre claras, não se dá uma continuidade nessas relações, é o famoso esgarçamento dos laços entre as pessoas e que provoca no fundo o sofrimento e a incompletude do sujeito, chegando hoje ser esse sentimento quase inerente a subjetividade.

O personagem parece atuar por puro id, ou seja, pelo desejo que se transformar em seus escritos. A 
censura não parece muito presente no espaço onde vive, ele brinca com possíveis repressores de sua personalidade, a tradição, a religiosidade da irmã e até a morte no diálogo com seu amigo falecido. Elementos interessantes como o sexo e a sexualidade, a medicalização das psicopatologias, o morto e a morte e a aparente indiferença pelo externo são em toda película referenciados. E este contexto é facilitado pelo ambiente, no caso Nova York que permite a seus moradores estímulos que parecem alimentar e retroalimentar suas neuroses.

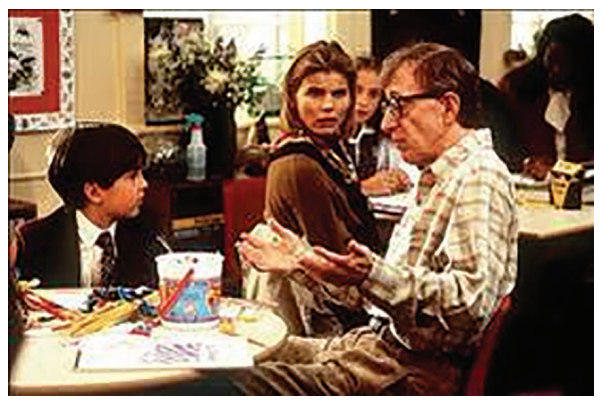

Figura 2

Podemos supor pelo filme que até os delírios terão conteúdos pertencentes aquele espaço nova iorquino. Isso porque pesquisas demonstraram que, por exemplo, em países religiosos os delírios tem maior cunho religioso do que quando comparados com não religiosos. Essa constatação faz então imaginarmos que os lugares colaboram muito na formação e atuação do sujeito em seu meio. Não se trata de um determinismo, mas devemos ter claro que nossa forma de agir e estar no mundo sempre se configura a partir do meio em que existimos, muito pela necessidade que este meio nos impõe.

A frase dita pelo personagem de que "a tradição é a ilusão da permanência" remete a questão da tentativa humana de eternidade presente nas religiões, nas premiações, nas academias imortais. A morte se faz presente concretamente para deixar clara a nossa finitude e para impor a necessidade de buscar um significado para este tempo entre o nascer e morrer por mais absurdo que possa aparecer.

A visão distorcida, que é característica também do personagem, aparece claramente numa metáfora onde a neurose é exatamente o conflito, onde certos impulsos inconscientes são incompatíveis com a realidade exterior ou são impossíveis de serem concretizados, desenvolvendo-se no sujeito um intenso estado de ansiedade e mal-estar geral.

Também no filme Vicky e Cristina Barcelona, temos questões parecidas, agora protagonizadas por mulheres.

Mudamos de cidade, Barcelona, a cidade mais charmosa com sua cultura bem diferente da americana e também como uma grande metrópole. O filme mostra talvez pouco dessa cidade, mas o americano gosta de mostrar a Europa com foco em outros valores, que são diversos dos deles. O prazer, a arte, as relações possuem um outro tempo, ou tem mais tempo para serem vividas e mais valorizadas, acho que isso é insinuado. Todavia as personagens não são espanholas, e há ali um confronto entre as americanas Vicky e Cristina e o casal espanhol.

A relação do casal pra lá de neurótica, serve como contraponto para mostrar a personalidade das duas mulheres americanas, muito diferentes entre si, mas no fundo com a mesma insatisfação provocada talvez pela vida de hoje. São muitas as opções para elas e nenhuma é satisfatória. Não apresentam problemas econômicos que talvez perturbasse ainda mais a vida e buscam um certo contentamento em suas existências. Uma mais audaciosa que a outra, mas ambas tentando se equilibrar no campo afetivo. Ou seja, esse campo de novo é o que tem mais relevo, e essa também é a questão do casal. Todos buscam o equilíbrio da forma como dá. A três, a dois, individualmente e esse caminho de busca é sinuoso, necessita de variações nas escolhas e uma dose extra de paciência e tempo, coisa que na cidade grande é quase impossível e talvez por isso, gere uma ansiedade recorrente nos personagens, quando não complicações ainda maiores de ordem psicológica.

No filme aparece que em alguns personagens, como a de Penélope Cruz, a dificuldade de descobrir o que é real e o que não é real, não é tão simples, pois as crenças no real podem ser confundidas com os delírios e alucinações.

A psicose pode ser provocada por uma rejeição primordial que consiste na expulsão de ideias ou pensamentos próprios, os quais passam a ser tratados como estranhos ou não acontecidos. Dessa rejeição, pode ocorrer a cisão do eu em duas partes, uma que é reconhecida e outra que não é reconhecida como sendo própria. Essa cisão caracteriza a patologia onde não sabemos onde começa a identidade de um e do outro.

Não se sabe no filme de fato quem é o grande artista se ele ou ela, o (a) grande artista. Na tríade relação amorosa também não se sabe quem é o real e o imaginário. Nesta relação complexa parece que a paranoia existe e é real. $\mathrm{O}$ interessante que Maria Elena (representada por Penélope) neste caso é cliente psiquiátrica de fato, com auto-agressidade em suas condutas destrutivas incluindo a mutilação e conduta suicida com ainda a heteroagressividade, chegando ao ponto de ameaças, disparos de tiros e tentativa de morte.

Mais uma vez a questão da morte aparece, remetendo a uma questão simples do amor, da posse e da dor. Ela se acredita dona dele e ele se acredita responsável por ela. Seu pensamento é egóico, permitindo que o id prevaleça sobre o superego, sua sedução é direta em função de uma praticidade dentro de sua lógica.

A posição das mulheres é bem interessante, elas parecem buscar a estabilidade de uma relação amorosa conjugando a vida sexual, já ele separa essas posições o que fica claro no convite às duas estrangeiras para irem ao local acolhedor, aprazível, 
divertido e com jogos sexuais sem rodeios ou preliminares. O que é aceito imediatamente por Cristina (Scarlett Johansson) e imediatamente negado pela Vick (Rebecca Hall), por estar para casar. Esta condição vai se alternar ao longo do filme de acordo com os espaços da morena e da loura.

Ele, Juan Antonio (Javier Bardem), indistintamente com qualquer possível parceira, busca realizar seus próprios desejos, o objeto do prazer é ele mesmo.

Cristina fica numa relação com o pintor, se acreditando estável, aceitando a ex-esposa, no mesmo espaço tem suas crenças alteradas em relação a mesma, com o passar do tempo se tornam íntimas, logo depois o relacionamento se configura numa tríade aparentemente estável até que ela percebe que não é o estilo de relação que ela demanda para sua vida, não do ponto de vista prático, mas aparentemente numa necessidade de sentido para sua vida.

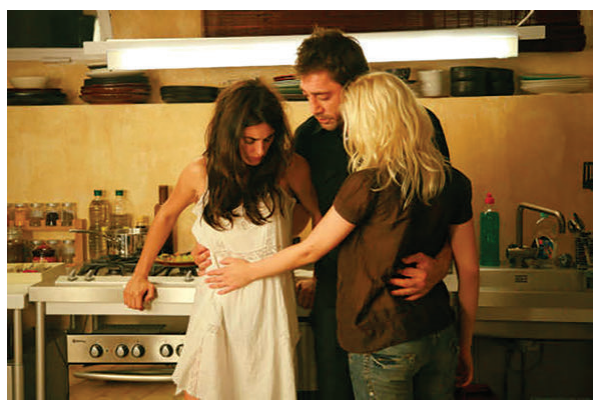

Figura 3

Vicky tem uma insatisfação no casamento e acredita que o pintor pode ser o grande amor de sua vida (paixão) e contrariando sua consciência e superando o superego parte para este relacionamento. Sua presença é inibida pela presença da ex-esposa.

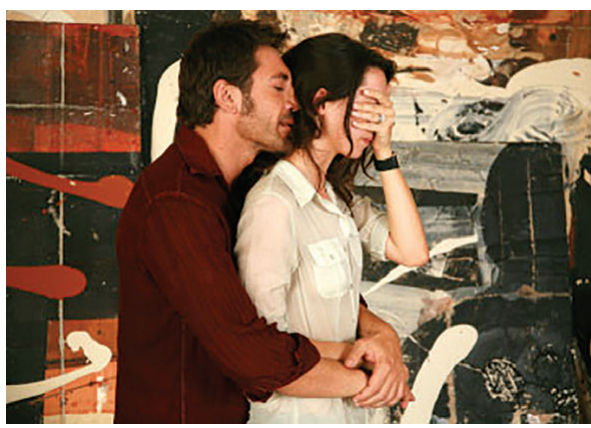

Figura 4

Percebemos então que todos possuem sintomas neuróticos que são definidos por Henry Ey como, perturbações dos comportamentos, dos sentimentos ou das ideias que manifestam uma defesa contra a angústia e constituem relativamente a este conflito interno um compromisso do qual o indivíduo, na sua posição neurótica tira certo proveito (benefício secundário da neurose). (Ey, 1963, p145)

Entretanto o exame mais detido dos personagens chama atenção para algo ainda mais complexo. Citando textualmente Freud,

Certo grau de fetichismo, portanto, está habitualmente presente no amor normal, especialmente naqueles seus estágios em que o objetivo sexual normal parece inatingível ou sua consumação é impedida. (Freud, 1976)

Ou seja, o fetichismo nesse caso acaba por se tornar, uma espécie de situação comum na vida amorosa do sujeito, assim como na arte, literatura, cinema, teatro, sendo os exemplos inesgotáveis. Mas, neste ponto, Freud, que é quem transita mais sobre essa questão, vem marcar a diferença, advertindo que

A situação só se torna patológica quando o anseio pelo fetiche passa além do ponto em que é meramente uma condição necessária ligada ao objeto sexual e efetivamente toma o lugar do objetivo normal, e, mais, quando o fetiche se desliga de um determinado indivíduo e se transforma no único objeto sexual.(Freud,1976)

Assim, diante de todas as questões patológicas ou não, presente nesse filme notamos que a abordagem se baseia no pressuposto de que o ser humano está em incessante busca de sentido e, considera o homem com estrutura para sua realização (Frankl, 1984). Cristina é o exemplo mais típico, no entanto, os outros personagens não ficam atrás. Ela é o mais típico, porque tem a consciência da busca e os outros talvez não a tenham ainda.

Dessa forma, o sentido da vida pode ser acessível à pessoa, independentemente de sua condição e não há algo que seja universal, pois que eles são individuais e transitórios, dependendo, assim, intrinsicamente do momento em que se faz presente (Frankl, 1989; Pereira, 2014). A busca pelo sentido está baseada numa tensão entre o "ser" e o "dever ser" - o princípio da noodinâmica - o que nos permite realizar valores objetivos no mundo externo. A vida tem um caráter de "chamamento", o ser humano é interrogado a todo o momento, e ele tem que responder e viver de acordo com o que tem sentido. A consciência é nosso órgão de sentido; pode ser definida como a capacidade de procurar e descobrir o sentido único e exclusivo oculto em cada situação. Portanto, o sentido precisa ser encontrado, descoberto a cada momento, está inerente à situação; não precisa ser criado.

De novo, Cristina e sua atitude de experimentação em todo filme mostra que na verdade esse sentido da vida é de fato algo transitório que não pode ser representado por uma satisfação eterna, mas tão somente por uma consciência de uma felicidade e satisfação momentânea, talvez o próprio sentido da impermanência das coisas. No momento em que a relação a três não mais a contentou ela partiu, daí Maria Elena dizer que ela tem uma insatisfação crônica, pois seu caminho é sempre a busca.

Para Frankl (2005), o vazio existencial pode ser 
definido como percepção de ausência de sentido, ou seja, é possível que pessoas não encontrem uma razão pela qual viver e diante disso sentem-se perdidas, infelizes e tendo dificuldade de saber o que fazer. Este vazio pode gerar angústia, oriunda do grau de tensão derivado dos questionamentos entre o que a pessoa é, e o que ela supõe que deveria ser, entre o que já alcançou e o que deveria alcançar, porém esta tensão não é patológica, mas indispensável ao bemestar mental do ser humano que necessita buscar um objetivo para que sua vida valha a pena ser vivida. Para o autor, o vazio existencial é ontológico, não patológico porém se experimentado reiteradamente quando a pessoa se nega a fazer uma leitura se seus sentimentos, desconsiderando a necessidade de dar uma resposta a este estado, pode gerar uma angústia sendo aí um outro estado denominado frustação existencial. Frankl (2005) lembra que esta pessoa também pode enxergar novas possibilidades a serem realizadas que irão, gradativamente, concretizar novos sentidos de vida. Ao experimentar o vazio existencial tendem a adotar estilos de vida para compensar a angústia e o sentimento de infelicidade que experimentam através do abuso de álcool ou outras substâncias, busca de realização imediata de prazer através de consumo exagerado, apreço desmedido ao poder para somente adquirir bens ou dominar outras pessoas, vivência predominante de prazer através do sexo, supondo que estas experiências possam trazer-Ihe felicidade. Nestes casos, segundo Frankl (2005), se o homem não refletir sobre as causas de seu sofrimento psíquico, se não se comprometer com a realização do bem sentir-se-á frágil para lutar contra o vazio existencial e poderá deixar-se dominar pelas determinações externas, sentindo-se infeliz no mundo, fazendo-se viver sem perspectivas. Este princípio que está subjacente na proposta de Frankl favorece a ajudar ao ser humano em busca de superação de seu sofrimento psíquico, pois pode se ver melhor como responsável por algo pelo qual vale à pena viver e sentir-se mais feliz e forte para superar as adversidades que Ihe abaterem ao longo da vida. Frankl (1991) analisando questões relativas à busca de sentido e vazio existencial, afirma que o desejo de sentido é, não apenas uma manifestação autêntica do humano, mas também indício de saúde mental.

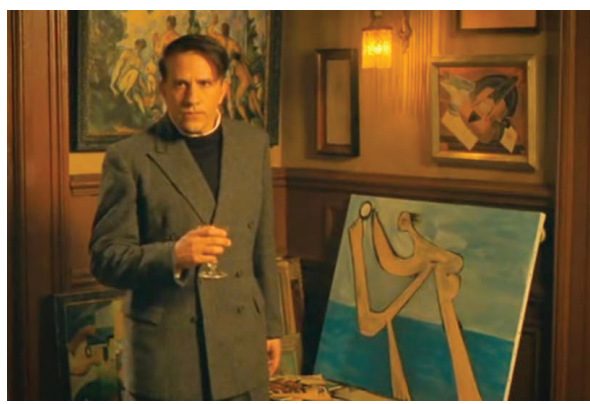

Figura 5
Não muito diferente nas abordagens é o terceiro filme, Meia noite em Paris, além de ser uma exaltação à cidade luz, trabalha a questão do tempo, o tempo de cada época e a insatisfação com o tempo presente que se vive. O personagem é de novo um escritor em uma relação insatisfatória dentro de uma família rica típica americana. Mas ele tem um inconformismo com sua arte e consigo mesmo. Queria estar no panteão da arte moderna com escritores, pintores, escultores que fizeram história e para lá ele se remete toda noite, como se o tempo presente fizesse a ele uma concessão de voltar a época em que pensa que se sentiria melhor em estar. Esse transporte para outra época se dá exatamente nos bairros boêmios, na rua, lugar de passagem onde tudo é possível acontecer, e o leva para a Paris das Vanguardas.

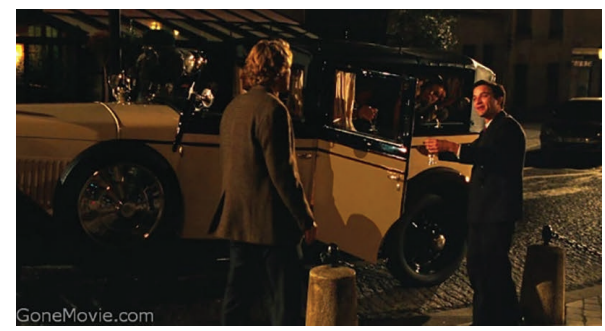

Figura 6

Ou seja, também ele tem uma questão psicológica que pode melhor ser pensada. A crença de que uma vivência que não é a dele, numa época que só conhece por livros, pudesse trazer boas memórias.

Sabemos que a memória é constantemente remodelada pelas configurações da dinâmica psíquica, sendo assim não podemos reduzir a influência da história do indivíduo a um determinismo linear do passado sobre o presente, pois que a memória que se tem pode a cada nova vivência ser ressignificada e isso de certa forma parece ser o que acontece no filme. Ao demarcar o glamour de Paris, uma cidade que remete à história, temos a crença de que o passado era mais e melhor que o presente. As musas eram mais lindas e puras com sex appel, os artistas e escritores mais intensos e brilhantes. Mas essa visão é pura imaginação do sujeito que lê e cria com a sua leitura a interpretação que quer, de acordo com seus desejos. Logo percebemos que o personagem é de novo um insatisfeito, descontente com o presente e sua fuga seria essa ilusão de um passado memoriável. Todavia essa exaltação e sobreposição do passado sobre o presente, só existe por conta de um juízo de valor imposto pelo sujeito a sua memória, que não é no entanto real, mas tão somente literária. Isto é, a partir de suas leituras o personagem tirou suas conclusões e valorizou mais o passado em detrimento do presente.

Conforme contribuições de Lukas (2012, p.159) "as pessoas que se encontram num "vazio existencial" permanecem doentes por mais tempo porque sua "força de mudança" não se acende", pois estavam primordialmente determinadas por autorrecriminações e queixas sobre o inevitável, tornando-se menos 
comprometidas com o desejo de viver, com o encantamento da possibilidade de realizações futuras, determinam-se pelo passado ou pelo presente, apenas, não experimentando projetar-se para além de si, esquecendo-se de si, para realizar o bem e, consequentemente experimentar felicidade.

Frankl (apud PINTOS, 2007) fala da capacidade de suportar o sofrimento como uma forma de realizar o sentido da vida através dos valores de atitude, pois para ele, esses valores só se realizam quando algo fatal precisa ser aceito tal como ele é, porém, é fundamental que a pessoa possa compreender o sentido dessa dor a ponto de transformar uma tragédia pessoal em uma vitória. Assim, o sofrimento passa a ter sentido e deixa de ser somente um sofrimento, sugerindo que é possível encontrar sentido para a vida mesmo vivenciando situações que causam algum tipo de dor. Esta forma de lidar com o sofrimento pressupõe a existência humana como ativa, pois as pessoas que enfrentam de maneira otimista os problemas, as dificuldades e o sofrimento que a vida lhes oferece devem sentir-se orgulhosas pelo amadurecimento adquirido durante toda essa caminhada decorrente do sofrimento suportado. Assim, nesta perspectiva, a vida do homem não vai ser considerada sem sentido mesmo frente a dor, pois a todo momento lhe é possível ressignificar a sua vida. "O ser humano é capaz de mudar o mundo para melhor, se possível, e de mudar a si mesmo para melhor, se necessário" (FRANKL, 2005, p. 112).

\section{Conclusão}

Dessa maneira sem fecharmos a possibilidade de muitas outras análises vemos que as três obras cinematográficas de Woody Allen, nos colocam reflexões que ultrapassam uma sessão de cinema construindo em nossos pensamentos interpretações variadas de acordo com a linha de estudo que nos remetemos. No entanto, uma questão se sobrepõem em todos os filmes, a busca de um sentido para a vida, que pode ser algo natural e saudável ou se transformar num problema para as pessoas e isso pode ser ainda mais acentuado quando vemos o esgarçamento das relações interpessoais nas cidade modernas.

\section{Bibliografia}

Bauman, Zygmunt. Amor Líquido - sobre a fragilidade dos laços humanos. Rio de Janeiro: Zahar, 2004.

Freitag, Barbara. Teorias da cidade. São Paulo, Papirus, 2012.

Freud, S. Três ensaios sobre a teoria da sexualidade. ESB. Rio de Janeiro: Imago,1976, v.VII.

Freud, S. (1988). Conferências introdutórias a psicanálise. O sentido dos sintomas. In: Obras completas de Sigmund Freud (Vol. 16, pp. 235-249). Buenos Aires, 1988.

Frankl, V. E. (1984). La idea psicológica del hombre (4. ed.). Madrid, España: Rialp.

Frankl, V. E. (1989). Psicoterapia e sentido da vida. São Paulo: Quadrante.
Frankl, Viktor E. Em Busca de Sentido. 2a ed. São Leopoldo: Sinodal, Petrópolis, Ed. Vozes 1991.

Leopoldo: Sinodal, 2005. Em Busca de Sentido. $21^{\mathrm{a}}$ ed. São Gomes, José C.V. Logoterapia: a Psicoterapia Existencial Humanista de Viktor Emil Frank. $2^{a}$ ed. São Paulo: Loyola, 1992.

Guattari, Félix. Caosmose- um novo paradigma estético. Rio de Janeiro: Editora 34, 1992.

Lukas, Elizabeth. Psicoterapia e Dignidade. $1^{\text {a }}$ ed. Ribeirão Preto, SP: IECVF, 2012.

Pintos, Claudio G. Frankl por definición: consultor temático de logoterapia y análisis existencial. $1^{\text {a }}$ ed. Buenos Aires: San Pablo, 2007.

\section{Filmografia}

Desconstruindo Harry. 1997. De Woody Allen. Estados Unidos.

Meia Noite em Paris. 2011. De Woody Allen. Estados Unidos.

Vicky Cristina Barcelona. 2008. De Woody Allen. Estados Unidos. 